\title{
Understanding and assessing vegetation health by in situ species and remote-sensing approaches
}

\author{
Angela Lausch $^{1,2 *}$ (i) | Olaf Bastian ${ }^{3}$ | Stefan Klotz ${ }^{4}$ (D) | Pedro J. Leitão ${ }^{2,5}$ (i) | \\ András Jung ${ }^{6,7}$ (D) | Duccio Rocchini ${ }^{8,9,10 ~(D) ~ \mid ~ M i c h a e l ~ E . ~ S c h a e p m a n ~}{ }^{11}$ (D) | \\ Andrew K. Skidmore ${ }^{12,13}$ (i) | Lutz Tischendorf ${ }^{14}$ | Sonja Knapp ${ }^{15}$
}

\begin{abstract}
${ }^{1}$ Department of Computational Landscape Ecology, Helmholtz Centre for Environmental Research-UFZ, Leipzig, Germany; ${ }^{2}$ Geography Department, Humboldt University Berlin, Berlin, Germany; ${ }^{3}$ OT Boxdorf, Moritzburg, Germany; ${ }^{4}$ Department of Community Ecology, Helmholtz Centre for Environmental Research-UFZ, Halle, Germany; ${ }^{5}$ Department Landscape Ecology and Environmental Systems Analysis, Technische Universität Braunschweig, Braunschweig, Germany; ${ }^{6}$ Technical Department, Szent István University, Budapest, Hungary; ${ }^{7}$ MTA-SZIE Plant Ecological Research Group, Szent István University, Budapest, Hungary; ${ }^{8}$ Center Agriculture Food Environment, University of Trento, Trento, Italy; ${ }^{9}$ Centre for Integrative Biology, University of Trento, Trento, Italy; ${ }^{10}$ Department of Biodiversity and Molecular Ecology, Research and Innovation Centre, Fondazione Edmund Mach, San Michele all'Adige, Italy; ${ }^{11}$ Remote Sensing Laboratories, Department of Geography, University of Zurich, Zurich, Switzerland; ${ }^{12}$ Faculty of Geo-Information Science and Earth Observation (ITC), University of Twente, Enschede, The Netherlands; ${ }^{13}$ Department of Environmental Science, Macquarie University, Sydney, NSW, Australia; ${ }^{14}$ ELUTIS Modelling and Consulting Inc., Ottawa, Ontario, Canada and ${ }^{15}$ Department of Community Ecology, Helmholtz Centre for Environmental Research-UFZ, Halle, Germany
\end{abstract}

Correspondence

Angela Lausch, Department of Computational Landscape Ecology, Helmholtz Centre for Environmental Research-UFZ, Permoserstr. 15, D-04318 Leipzig, Germany.

Email: angela.lausch@ufz.de

Handling Editor: Petteri Vihervaara

\section{Abstract}

1. Human activities exert stress on and create disturbances to ecosystems, decreasing their diversity, resilience and ultimately the health of ecosystems and their vegetation. In environments with rapid changes in vegetation health (VH), progress is needed when it comes to monitoring these changes and underlying causes. There are different approaches to monitoring $\mathrm{VH}$ such as in situ species approaches and the remote-sensing approach.

2. Here we provide an overview of in situ species approaches, that is, the biological, the phylogenetic, and the morphological species concept, as well as an overview of the remote-sensing spectral trait/spectral trait variations concept to monitor the status of $\mathrm{VH}$ as well as processes of stress, disturbances, and resource limitations affecting $\mathrm{VH}$. The approaches are compared with regard to their suitability for monitoring $\mathrm{VH}$, and their advantages, disadvantages, potential, and requirements for being linked are discussed.

3. No single approach is sufficient to monitor the complexity and multidimensionality of VH over the short to long term and on local to global scales. Rather, every approach has its pros and cons, making it all the more necessary to link approaches. In this paper, we present a framework and list crucial requirements for coupling approaches and integrating additional monitoring elements to form a multisource vegetation health monitoring network (MUSO-VH-MN).

4. When it comes to linking the different approaches, data, information, models or platforms in a MUSO-VH-MN, big data with its complexity and syntactic and semantic heterogeneity and the lack of standardized approaches and $\mathrm{VH}$ protocols pose the 
greatest challenge. Therefore, Data Science with the elements of (a) digitalization, (b) semantification, (c) ontologization, (d) standardization, (e) Open Science, as well as (f) open and easy analyzing tools for assessing $\mathrm{VH}$ are important requirements for monitoring, linking, analyzing, and forecasting complex and multidimensional changes in $\mathrm{VH}$.

\section{KEYWORDS}

biological species concept, earth observation, morphological species concept, multi-source vegetation health monitoring network, phylogenetic species concept, remote-sensing, remote-sensing spectral trait, spectral traits variation concept

\section{1 | INTRODUCTION}

An extreme loss of biodiversity has been shown to reduce both ecosystem stability and a range of ecosystem functions (Cardinale et al., 2012). This loss can occur at different levels of biotic organization from the molecular, individual and community levels to that of ecosystems. Accordingly, biodiversity is one central component of the concepts of ecosystem health and integrity (Haase et al. 2018; Müller, 2005; Rapport, Costanza, \& McMichael, 1998). These concepts relate to the self-organizing capacity of ecosystems in the presence of stress. Healthy ecosystems can thus be seen as vigorous, diverse systems that are characterized by a high resilience, that is, the ability to quickly return to an initial state following an external disturbance and thus to withstand negative impacts from external influences (Rapport et al., 1998).

Effects of stress, disturbances, and resource limitations on ecosystem health are mostly nonlinear on a spatial and temporal scale complex, and multidimensional. Evolutionary adaption processes, regional contexts, and stress interactions can impede the understanding and monitoring of ecosystem health (Lausch, Erasmi, King, Magdon, \& Heurich, 2016, 2017). Consequently, a holistic approach is required to monitor, analyse, and evaluate ecosystem health. Such an approach should enable landscape managers, decision makers, and politicians to react more quickly and in targeted ways to decreasing ecosystem health and to perform monitoring and data-driven ecosystem management in an effort to stabilize resilience. However, to date, a big discrepancy exists between the requirements and the reality of monitoring: High spatial-temporal exactness and short to long-term timely resolution from local to global scales are needed, that can be recorded cost-effectively, quickly, and comparably, using standardized testing procedures. Moreover, dealing with and managing big and complex monitoring data impedes data retention, linking as well as analyzability.

Here, we focus on vegetation and vegetation health $(\mathrm{VH})$ as the level of primary producers within ecosystems. To record shifts in vegetation diversity (VD) and related shifts in $\mathrm{VH}$, two main monitoring methods are available: (a) in situ or field-based observation and (b) remote-sensing (RS) approaches. In situ observation refers to the direct identification and monitoring of plant species by taxonomists and has been used for $\mathrm{VH}$ monitoring for a long time (Mueller, Baessler, Schubert, \& Klotz, 2010). In situ approaches are the basis for our present-day understanding of biodiversity, macroecology and biogeography (Violle, Reich, Pacala, Enquist, \& Kattge, 2014). Here, plant species are recorded and systematized on the basis of different species concepts (Wheeler \& Meier, 2000). However, in-situ approaches on the basis of taxonomic units are spatially and temporally limited when it comes to understanding species responses to stress, disturbances, or resource limitations posed by environmental conditions (Soberón, 2007). While in situ observation has largely been based on taxonomic units, the importance of species traits has recently been recognized and has allowed for a whole new way of understanding fundamental ecological questions, such as "why organisms live where they do and how they will respond to environmental change" (Green, Bohannan, \& Whitaker, 2008: 1039). In situ species trait approaches give a complex understanding of species' potential with respect to different stress levels, disturbances, or resource limitations, adaptation mechanisms, plant fitness or resilience of vegetation. Still, they are limited when it comes to producing extensive conclusions, because in situ mapping is mostly restricted to point samples or small areas and it is costly.

In contrast to in situ approaches, RS observation is entirely based on spectral reflectance values captured by sensors mounted on drones, airplanes, or satellites. RS approaches for $\mathrm{VH}$ monitoring constitute the only approach for a timely, cost-effective, objective, and repeatable recording and assessment of status, stress, disturbance, and resource limitations over the short to long term and for local and global vegetation monitoring (Skidmore et al., 2015; Turner, 2014). Historically, RS evaluations focused on categorizing discrete vegetation units and were the basis of land-use-land-cover classification approaches (Ustin \& Gamon, 2010). However, the development of RS techniques with better radiometric, spatial, spectral, directional, and temporal resolution and the enhanced understanding of the importance of spatial heterogeneity and continuous information rather than discrete vegetation units or land-cover classes (Lausch, Blaschke, et al., 2015) to describe processes of stress, disturbances, or resource limitations are opening up new perspectives and new applications of RS in the context of $\mathrm{VH}$.

The RS approach makes it possible to respond to a number of questions related to the status and changes of ecosystem functions, to assess disruptions in ecosystem processes, to measure spatial-temporal shifts in plant phenology (Cleland, Chuine, Menzel, 
Mooney, \& Schwartz, 2007; Garonna, de Jong, \& Schaepman, 2016; Jeong, Ho, Gim, \& Brown, 2011) to analyse effects of climate change on vegetation (Schimel, Asner, \& Moorcroft, 2013) to monitor landuse intensity (Gómez Giménez, de Jong, Della Peruta, Keller, \& Schaepman, 2017), land-use changes, landscape fragmentation, infestation and the spread of insect pests in forests and crops, right up to species distribution and richness ( $\alpha$-diversity) (Rocchini, Hernández-Stefanoni, \& He, 2015), turnover in species composition ( $\beta$-diversity) (Baldeck \& Asner, 2013; Rocchini et al., 2017), and spatial-temporal heterogeneity in vegetation (Rocchini et al., 2010) as well as phylodiversity (Asner \& Martin, 2016), taxonomic (Rocchini et al., 2018), structural (Leitão et al., 2015) and functional (Schneider et al., 2017) VD. But, the RS approach for monitoring VH is limited by the following constraints. Only specific plant traits, trait combinations, and trait variations can be recorded by RS (Lausch, Erasmi, et al., 2016). Moreover, the shape, density, and distribution of plant traits in space and over time determine (a) the spatial, spectral, radiometric, and temporal characteristics of the RS sensors, (b) the choice of the classification method, be it pixel-based or (geographic) object-based approach, and (c) "how the RS algorithm and its assumptions fit the RS data and the spectral traits (ST) of the plant species" (Lausch, Bannehr, et al., 2016).

Consequently, no single approach is suitable for monitoring $\mathrm{VH}$ in all its complexity and multidimensionality over short to long-term periods and on local to global scales. With this in mind, the goal of the paper is: (a) To define $\mathrm{VH}$ and to introduce methods to measure $\mathrm{VH}$; (b) to identify the key characteristics, differences and commonalities among in situ and RS-based VH mapping approaches and to identify ways of integrating both approaches; (c) to present a framework and crucial requirements for combining in situ and RS-based approaches and the development of a multi-source $\mathrm{VH}$ monitoring network.

\section{2 | IN SITU APPROACHES FOR MONITORING VH}

Species concepts group individuals according to shared characteristics (Wheeler \& Meier, 2000). There are various approaches, with the most important being the biological species concept (BSC; Mayr, 1942) relating to taxonomic diversity; the phylogenetic species concept (PSC; Eldredge \& Cracraft, 1980) relating to phylodiversity; and the morphological species concept (MSC; Mayr, 1969) relating to traits and functional diversity.

\section{1 | BSC-to measure stress in taxonomic diversity}

The BSC defines species on the basis of the ability of individuals to interbreed and have fertile offspring, not on the basis of specific visible (and possibly plastic) traits (Mayr \& Ashlock, 1969). This makes the definition of species identity relatively stable. Species are the basis for the quantification of measures of taxonomic diversity from which we can follow changes in biodiversity due to changes in land use or climate. Species richness is positively related to some ecosystem functions, such as productivity (Grace et al., 2016) and enhances the resistance of ecosystem productivity to climate events (Isbell et al., 2015) or to disturbances such as flooding (Wright et al., 2017). Consequently, monitoring taxonomic diversity helps monitoring $\mathrm{VH}$. Even the sole distinction of species by in situ approaches can provide insights into the state of biodiversity and related ecosystem functions. Taxonomic diversity has thus been counted as one of the essential biodiversity variables (EBV) of the Group of Earth Observations Biodiversity Observation Network (Pereira et al., 2013). However, by solely considering taxonomic diversity, we cannot infer information on for example, the rarity of a species or whether it is native, exotic or invasive in a region. Where such information is available (e.g. from national red lists or inventories of invasive species, for example, DAISIE (Pyšek et al., 2010), the distinction of species by in situ approaches can be used for mapping the distribution, spread or decline of for example, invasive species.

\section{2 | PSC-to measure stress in phylodiversity}

The knowledge about phylodiversity can provide better understanding of VH (Faith, 1992; Marcon \& Hérault, 2015). Measures of phylodiversity (diversity measures based on the evolutionary history of species; Laity et al., 2015) do not necessarily correlate to measures of taxonomic diversity (Schweiger, Klotz, Durka, \& Kühn, 2008). Rather, an increase in taxonomic diversity can just as well be accompanied by a decrease in phylodiversity (Knapp, Winter, \& Klotz, 2017). Phylodiversity is not distributed randomly across the globe (Sechrest et al., 2002) and is affected by land use (Frishkoff, Karp, M'Gonigle, Hadly, \& Daily, 2014; Knapp, Kühn, Schweiger, \& Klotz, 2008) climate (Willis, Ruhfel, Primack, Miller-Rushing, \& Davis, 2008) biological invasions and extinctions (Knapp et al., 2017). The phylodiversity of plants has been shown to increase the taxonomic diversity of arthropods (Dinnage, Cadotte, Haddad, Crutsinger, \& Tilman, 2012) and to support ecosystem functions and stability (Cadotte, 2013; Flynn, Mirotchnick, Jain, Palmer, \& Naeem, 2011). It has been suggested as criterion for the establishment of protected areas (Sechrest et al., 2002). In sum, measures of phylodiversity can provide important insights into $\mathrm{VH}$; however, in situ, phylodiversity cannot be monitored directly but needs to be inferred from information on species occurrence.

\subsection{MSC-to measure stress in functional diversity}

BSC and PSC distinguish species based on the ability of individuals to interbreed. In contrast, the morphological (Mayr, 1969), the chemotaxonomy (Grube \& Kroken, 2016) and environmental species concepts (Hutchinson, 1965) focus on the characteristics of species-the so-called traits-and on the adaptation of species to environmental conditions. Taxonomic measures cannot answer "why organisms live where they do and how they will respond to environmental change" (Green et al., 2008: 1039) but trait-based/functional approaches can. 
Plant traits are anatomical, morphological, biochemical, physiological, structural or phenological characteristics of plants (Kattge et al., 2011). As environments differ in the presence and frequency of trait values ("environmental filtering"; Figure 2), traits, their diversity, and their changes can be used to map environmental changes as well as impacts from and responses to environmental and anthropogenic pressures (Carboni et al., 2014; Garnier et al., 2007), such as plant invasions (van Kleunen, Weber, \& Fischer, 2010), grazing (Díaz et al., 2007) or eutrophication and fragmentation (Römermann, Tackenberg, Jackel, \& Poschlod, 2008). The diversity of traits (i.e. functional diversity) has been shown to support ecosystem functioning (Flynn et al., 2011). The fact that traits both respond to environmental changes and affect ecosystems makes them valuable indicators for $\mathrm{VH}$.

Traits can show plastic responses to environmental changes but can also be evolutionary fixed (Cheptou, Carrue, Rouifed, \& Cantarel, 2008). Consequently, in comparison to the BSC, the definition of traits is less stable. Standardized measurements are thus needed to compare traits across sites and scales. However, in situ trait measurements are time consuming and many measurements require laboratory equipment (e.g. measuring leaf nitrogen or chlorophyll content). Nevertheless, a range of traits has been measured by in situ approaches and has been stored in national or global databases (Kattge et al., 2011). Even though such databases exist, the extrapolation of trait patterns remains limited. Only spatially and temporally intensive data collection, such as concentrating data sampling to long-term ecological research sites (Mueller et al., 2010) or monitoring biodiversity-ecosystem functioning experiments (Bruelheide et al., 2014) allow a comprehensive description, explanation and prediction of trait changes and related changes in $\mathrm{VH}$.

\section{3 | REMOTE-SENSING APPROACHES FOR MONITORING VH}

RS records biochemical-biophysical, physiognomic, morphological, structural and functional traits at all levels of biotic organization based on the principles of image spectroscopy across the electromagnetic spectrum from visible to microwave bands (Ustin \& Gamon, 2010). Compared to the in situ trait approach, RS is unable to detect all traits and trait variations (Homolová, Maenovsky, Clevers, GarciaSantos, \& Schaepman, 2013). Traits and trait variations that can be monitored by RS are called ST (see Figure 1) and spectral trait variations (STV) (see Figure 2) (Lausch, Erasmi, et al., 2016). The approach to monitor VH by RS is called the remote-sensing-spectral trait/STV concept (RS-ST/STV-C).

\section{1 | Remote sensing can measure processes, stress, disturbances, and resource limitations}

RS can record the status, stress, disturbances, or resource limitations of vegetation over the short and long term on local and global scales, since (modified after Lausch, Erasmi, et al., 2016)
1. processes, stress, disturbances, and resource-limitations cause changes in spectral traits and lead to STV,

2. plant traits are a proxy and filter for status (structure, process, function) and for stress, disturbances, or resource limitations,

3. RS can record direct and/or indirect traits and trait variations on all spatial and temporal scales of vegetation hierarchy (see Figure 2),

4. spectral RS patterns and heterogeneity are a proxy for plant trait diversity and the result of processes, stress, disturbances and resource limitations on plant and vegetation traits.

\subsection{Monitoring stress in phylo-, taxonomic, structural and functional diversity by RS}

\subsection{1 | Phylogenetic stress by RS}

Phylodiversity has been suggested as a proxy of functional diversity because a range of functional traits are heritable; still, heritability does not always apply (Lososová et al., 2016). Inferring facts on phylodiversity from spectral traits should thus only be possible when heritable traits correlate with spectral traits or when spectral traits are heritable themselves (Jetz et al., 2016). Imaging spectroscopy with its high spectral resolutions of $0.4-2.5 \mu \mathrm{m}$ and more than 20 spectral channels shapes the next generation of plant trait monitoring techniques compared to multispectral RS sensors (Asner \& Martin, 2016). By means of imaging spectroscopy at least 21 biochemical elements were identified, like foliar nitrogen content (Knyazikhin et al., 2013), photosynthetic pigments (Ustin et al., 2009), lignin, polyphenols and cellulose or water in leaves (Martin et al., 2018). These elements define the "spectral fingerprint" of plant species and vegetation based on their "chemical phylogeny" or chemical VD (Asner \& Martin, 2016; Pandey, Ge, Stoerger, \& Schnable, 2017; Ustin, 2013), Schweiger et al. (2018) developed an integrative spectral diversity indicator on the basis of the leaf economic spectrum (Díaz et al., 2015 ) to predict $97 \%$ of phylogenetic diversity in plant species.

\subsection{2 | Taxonomic stress by RS}

Plant species diversity, heterogeneity and richness are key parameters for describing $\mathrm{VH}$, stability and resilience of ecosystems (Richter, Reu, Wirth, \& Doktor, 2016). Therefore, a continuous and consistent recording of taxonomic stress by RS is a crucial method for assessing $\mathrm{VH}$. Due to their high spectral resolution and the recordability of various plant traits, hyperspectral RS techniques are very suitable for discriminating species and their turnover (Rocchini et al., 2017) floristic compositions (Lopatin, Fassnacht, Kattenborn, \& Schmidtlein, 2017) spatial heterogeneity (Rocchini et al., 2018) dominant species, functional guilds, invasive plant species (Santos, Khanna, Hestir, Greenberg, \& Ustin, 2016) or vegetation types (Laurin et al., 2016; Schmidt \& Skidmore, 2003).

However, different taxa can only be discriminated by RS if the taxa can be differentiated by: (a) their chemical, biochemical-biophysical, 
Spectral traits (ST) of plants with remote sensing (RS)

\begin{tabular}{|c|c|c|}
\hline $\begin{array}{l}\text { Biochemical \& biophysical ST } \\
: \quad \text { Chlorophyll a,b } \\
\text { a, } \beta \text { Carotene } \\
\text { Xanthophyll } \\
\text { Protein } \\
: \quad \text { Nitrogen } \\
: \quad \text { Phosphorous } \\
: \quad \text { Cellulose } \\
\text { Oil } \\
: \quad \text { Plant water } \\
: \quad \text { Sax } \\
\text { Starch } \\
\text { Sugar } \\
\text { Carbon }\end{array}$ & $\begin{array}{ll}\text { Physiognomic \& morphological } \\
\text { ST }\end{array}$ & 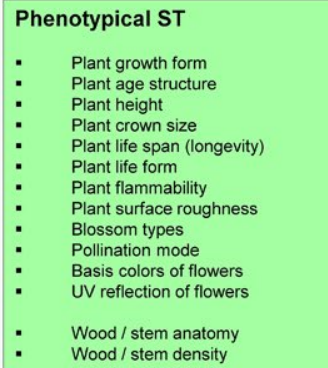 \\
\hline $\begin{array}{l}\text { Physiological \& functional ST } \\
\quad \text { Photosynthetic } \\
\text { Photosynthetic pathway } \\
\text { Photosynthesis capacity } \\
\text { Sun-induced fluorescence } \\
\quad \text { Spectroscopy } \\
\quad \text { Stomata conductivity }\end{array}$ & $\begin{array}{l}\text { Phenology \& senescence ST } \\
: \quad \text { Leaf phenology type } \\
: \quad \text { Plowering phenology } \\
\text { Plant phenology } \\
\quad \text { Land surface phenology }\end{array}$ & \\
\hline $\begin{array}{ll}\text { Evapotranspiration } \\
\text { : } & \text { Litrogen fixation capacity } \\
\text { : } \quad \text { Leaf absorbance } & \text { Leaf penductance } \\
\text { Nutrient retence } \\
\end{array}$ & $\begin{array}{l}\text { Phylogenetic ST } \\
: \quad \text { Phylogenetic content } \\
: \quad \text { Phylogenetic elements } \\
: \quad \text { Phylogenetic structure } \\
\end{array}$ & 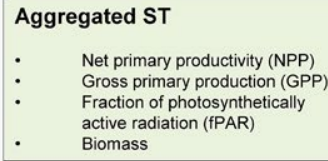 \\
\hline $\begin{array}{l}\text { Structural ST } \\
: \quad \text { Composition, configuration } \\
\text { Area, density, size, shape } \\
\text { Fragmentation } \\
\text { Spatial distribution } \\
\text { Patterns } \\
\text { Homogeneity, heterogeneity } \\
\text { Abundance } \\
\text { Diversity } \\
\text { Neighbourhood relationships } \\
\text { Connectivity } \\
\text { Complexity } \\
\text { Extent } \\
\text { 2D / 3D architecture \& layering } \\
\text { Leaf area index (LAI) }\end{array}$ & $\begin{array}{ll}\text { Stress, adaptation \& disturbance } \mathbf{S T} \\
: \quad \text { Plant tolerance to stress } \\
\text { Ecological strategy types } \\
\text { Ellenberg indicator values } \\
\text { Damage, disturbance } \\
\text { Invasive Species } \\
\text { : } \quad \text { Uemeroby } \\
: \quad \text { Naturalyness } \\
\text { Vulnerability } \\
\quad \text { Land-use-intensity }\end{array}$ & $\begin{array}{l}\begin{array}{l}\text { Chorology, distribution \& } \\
\text { dispersal ST }\end{array} \\
\text { Dispersal mode } \\
\text { Floristic zones } \\
\text { Floristic areas } \\
\text { Gradient traits } \\
\text { Climate, soil, water, altitude, } \\
\text { vegetation structure, biotic } \\
\text { interactions }\end{array}$ \\
\hline
\end{tabular}

Constraints of RS for monitoring vegetation health

FIGURE 1 Spectral traits for observing and assessing phylogenetic, taxonomic, structural and functional diversity using hyperspectral remote-sensing techniques (modified after (Lausch, Erasmi, et al., 2016). RS: remote sensing

morphometric, geometric or physiology traits, (b) various life-cycle traits like senescence, phenology, flowering period or growth characteristics; (c) if regional specific resource limitations are present, which determine the geographic presence of the plant species, or (4) if taxa can be differentiated by their response to stress, again using traits such as hairy leaves, leaf morphology, cuticula strength, changes to intercellular tissue.

The recording of taxonomic stress by multitemporal RS techniques (a combination of RS sensors with different characteristics such as thermal, optical or radar) as well as multisensor RS techniques (a combination of image data that covers the entire vegetation development) can generally be improved, since different sensors with different sensor characteristics increase the discrimination of various traits.

\subsection{3 | Functional stress by RS}

Plant traits both respond to and affect environmental conditions and can thus be used as indicators of stress, disturbances and resource limitations. Furthermore, functional VD is closely related to ecosystem processes such as water, matter and energy cycles (all being indicators of ecological integrity (EI) and thus of ecosystem health; (Haase et al., 2018). The open data policy of remote-sensing data and data products (Wulder \& Coops, 2014) like Landsat TM or the Copernicus RS mission (Sentinel 1-6) enable scientists to globally record data on the functional composition and diversity of plant communities as a basis for monitoring, understanding, assessing, evaluating and predicting, for example, the productivity of ecosystems (Lees, Quaife, Artz, Khomik, \& Clark, 2018) forest biomass (Avitabile et al., 2016) or vegetation productivity patterns (Guay et al., 2014), estimating carbon fluxes (Lees et al., 2018; Schimmel et al., 2015), changes in carbon stocks (Asner et al., 2014) or interactions between biodiversity and carbon stocks (Bustamante et al., 2016). The global variation in leaf respiration in relation to plant functional types, leaf traits and climate (Atkin et al., 2015), the distribution of $\mathrm{N}$ in canopies (Balzotti et al., 2016) or the loss of canopy water (Asner et al., 2015) can all be monitored extensively by using RS technologies. Furthermore, there are numerous applications for monitoring shifts in plant traits such as shifts in biochemical traits, photosynthetic activity, plant productivity, phenology, the length of the growing season, 
Process (a) $\rightarrow$ vegetation reactions $\rightarrow$ changes in traits $\rightarrow$ leading to trait variations (b) $\rightarrow$ spectral responses in remote sensing data (c)

(a)

Process

Land-use

intensity

(b)

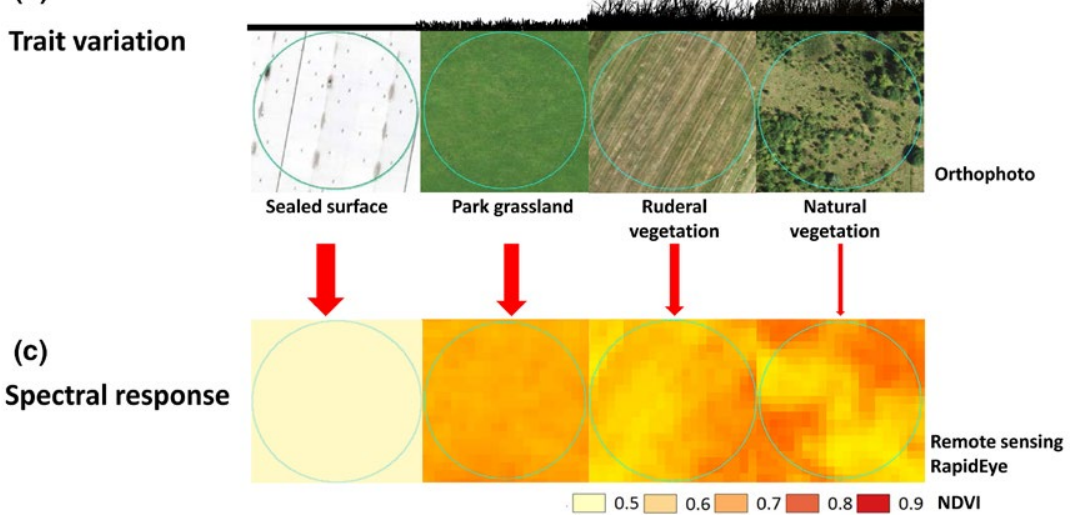

FIGURE 2 Illustration of environmental filtering of vegetation by processes of land-use intensity and how remote sensing can monitor this.

(a) Processes of land-use intensity lead to reactions in the vegetation and changes in traits, which lead to (b) trait variations with the result of (c) the spectral response that can be measured using remote-sensing data. NDVI (Normalized Difference Vegetation Index) is a proxy for the spectral trait-chlorophyll content (modified after Wellmann et al., 2018) the variation in carbon dioxide exchange, and carbon balance or greening response (Garonna et al., 2016). An extensive overview on this is provided in (Lausch, Erasmi, et al., 2016).

The "Fluorescence Explorer Satellite" (FLEX) is currently being developed and is financed and established by European Space Agency (ESA). It is scheduled for use after 2022 (Kraft, Del Bello, Bouvet, Drusch, \& Moreno, 2012). It features a high spectral resolution of 0.3-3.0 $\mathrm{nm}$ to directly measure solar-induced chlorophyll fluorescence as an indicator of photosynthetic conditions and to provide estimates of global photosynthetic activity and $\mathrm{CO}_{2}$ fluxes (Kraft et al., 2012). The development of high temporal and spectral resolution for future applications is underway: the first hyperspectral satellite EnMAP, the hyperspectral/thermal combination HyspIRI and the multispectral/hyperspectral RS combination HISIRI, or a multi-sensor combination with RADAR and thermal radiometer like the ECOsystem Spaceborne Thermal Radiometer Experiment on Space Station.

\section{4 | COUPLING OF IN SITU AND RS APPROACHES BY METHODS OF DATA SCIENCE}

No monitoring approach alone is sufficient, comprehensive, costeffective, and flexible enough to perform $\mathrm{VH}$ monitoring from local to global scales and for short to long-term processes as well as to monitor changes in phylo-, taxonomic and functional diversity and to assess the stress and resilience of ecosystems. Therefore, the development of a multisource vegetation health monitoring network (MUSO-VH-MN) is necessary where multisource data and different monitoring approaches can be linked in an effort to compensate for the shortcomings of one approach with the advantages of another and to achieve additional benefits for $\mathrm{VH}$ monitoring. A future MUSO-VH-MN therefore should contain the following elements: (a) the integration of multisource data and platforms, (b) the coupling of monitoring approaches and (c) Data Science as a bridge for coupling (Figure 3), (modified after Lausch et al., in review).

\section{1 | Data, networks and platforms}

The MUSO-VH-MN should integrate the following data and site survey platforms. Species/habitats: Data of site surveys for species, species lists, metabarcoding, microgenomics (Bush et al., 2017), Phenotyping (Deans et al., 2015), data from museums, lysimeter, plant phenomic facilities (Furbank, 2009), controlled environmental facility-Ecotron's (Lawton et al., 1993), long-term ecological research (Mueller et al., 2010), spectral laboratory experiments, biodiversity ecosystem functioning experiments (Bruelheide et al., 2014), Remote sensing: Optical (multispectral, hyperspectral), thermal, Radar, LiDAR data, laboratory, tower, camera traps, wireless sensor networks, drones, close-range, air- and spaceborne RS platforms, Additional: linking monitoring databases, networks, citizen science information, abiotic (soil, water, air), social and economic information. 


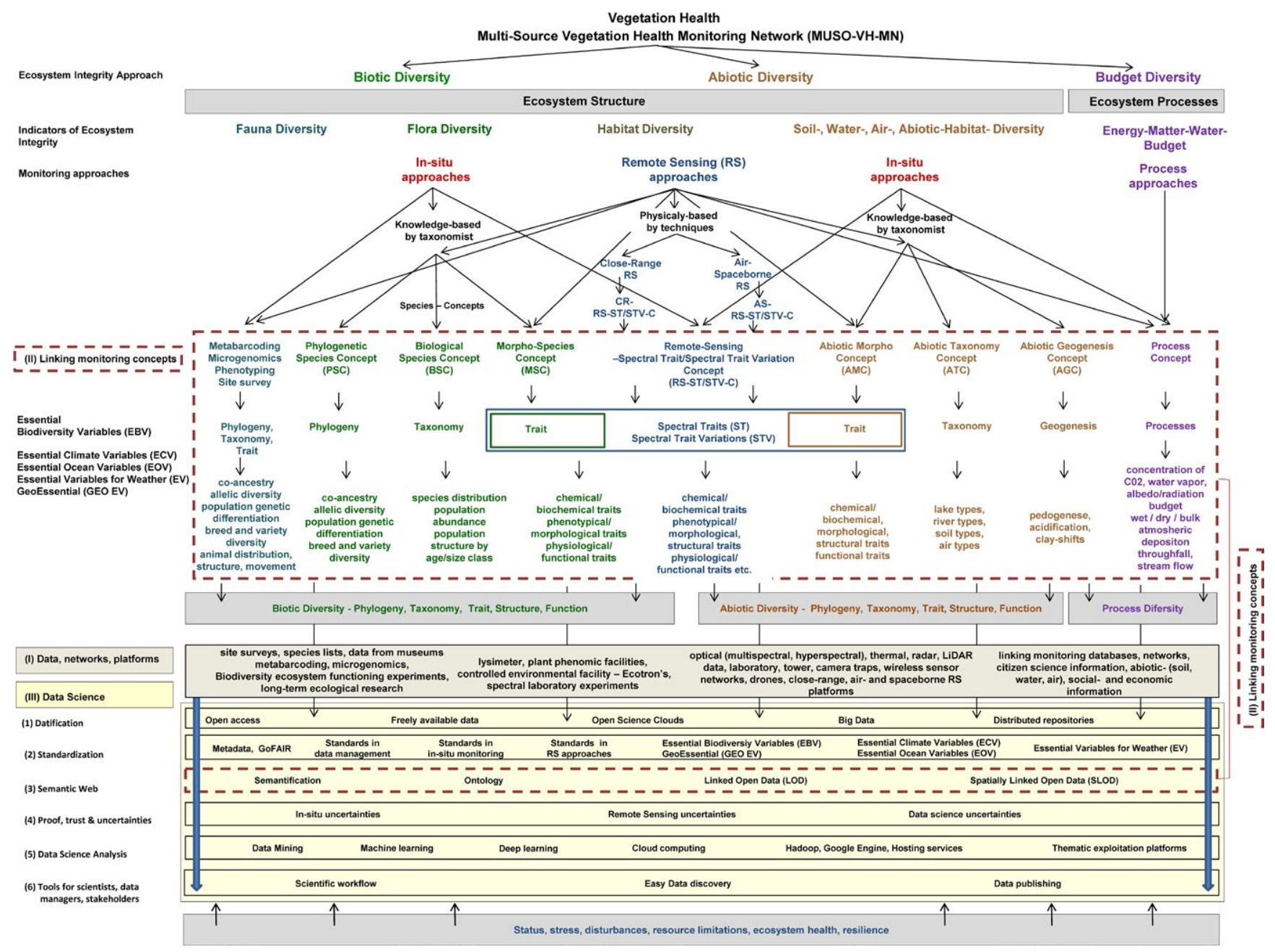

FIGURE 3 Illustration of the components that need to be included for a future multi-source vegetation health monitoring network: (I) integration of existing data, networks and platforms, (II) linking of existing monitoring approaches as well as (III) the use of data science as a bridge for handling and coupling big forest health data with volume, velocity, variety and veracity, close-range remote-sensing-spectral trait/spectral trait variation-concept, air-scaceborne remote-sensing-spectral trait/spectral trait variation-concept

\subsection{Linking monitoring approaches}

Future site-based long-term research and monitoring concepts necessitate the linking of different approaches, namely: (a) for vegetation monitoring-the Biological (BSC), the Phylogenetic (PSC), and the MSC, (Jetz et al., 2016), (b) the concepts of phenotyps (Deans et al., 2015), (c) for abiotic and process monitoring-the concept of EI (Haase et al., 2018) and (d) for RS-ST/STV-C (Lausch, Bannehr, et al., 2016).

\subsection{Data science as a bridge}

When it comes to developing a MUSO-VH-MN, big data, complexity and syntactic and semantic heterogeneity and the lack of standardized approaches, protocols, as well as data management are all challenging. This is where Data Science comes in as a bridge: (a) digitalization, (b) standardization, (c) Semantic Web, (d) testing of uncertainties, (e) Data Science analysis, and (f) open and easy analysis tools for assessing VD are all crucial requirements for a better use, understanding, and analysis of complex and multidimensional VD. Specifically, this means:

1. Digitalization: VD information has to be computer producible, connectable, readable, and evaluable, allowing for a cost-effective, error-free and standardized processing and semantic linking of complex and multidimensional VD information to understand new patterns, interactions and processes in ecosystems. Important components are: Open Access for tools, software, algorithms, instruments or platforms, freely available data and data policy for species, RS (Wulder \& Coops, 2014) and abiotic data, development of Open Science Clouds like the European Open Science Cloud (Ayris et al., 2016), familiarization with big data and distributed repositories.

2. Standardization: Data, information, tools, algorithms, models, data management, and monitoring of approaches have to be standardized, administered, stored, processed, updated as well as linked and evaluated with other platforms and 
networks. The basics of metadata management reflect the principles of Findability, Accessibility, Interoperability and Reusability (Wilkinson, Dumontier, Aalversberg, Appleton, \& Axton, 2016). The concepts of EBV (Pereira et al., 2013), essential climate variables or semantic-based platforms like GFBio (https://www.gfbio.org) are leading the way for standardization.

3. Semantic web: Linking complex and multidimensional VD information, tools, approaches, data, scales, RS platforms, models in a semantic-enabling way according to the standards of the World Wide Web Consortium (Berners-Lee, 2006). Important elements are: semantification (Berners-Lee, 2006), ontologization (Madin, Bowers, Schildhauer, \& Jones, 2008) and Linked Open Data approaches (Lausch, Schmidt, \& Tischendorf, 2015).

4. Proof, trust and uncertainties: Most methods, data or models used in data science introduce a certain degree of uncertainty. Consequently, methods of testing uncertainties are required for in-situ, RS-monitoring data and Data Science approaches.

5. Data-science-analysis: The digitalization of the world and necessitates the use and familiarization with Big Data and its four charac teristics: Data volume, velocity, variety and veracity. Data Science analysis thus requires methods of Data Mining, Machine learning, Cloud computing, Hadoop, Google Engine, Hosting services and Thematic exploitation platforms.

6. Tools for scientists, data managers and stakeholders: Open and easy management and analysis tools, comprehensible scientific workflows as well as easy and constantly up to date data publishing tools for analyzing and assessing MUSO-VH-MN information are imperative for an applicable and implementable decision-making support system for authorities, stakeholders and politicians.

\section{5 | CONCLUSION}

$\mathrm{VH}$ is multi-dimensional and only partially understood due to its complexity. So far there is no existing monitoring approach that can sufficiently assess and predict $\mathrm{VH}$ and its resilience on its own. To establish a multi-source $\mathrm{VH}$ monitoring network in the future, the following main elements should therefore be considered: (a) the integration of existing data, networks and platforms, (b) the linking of all existing monitoring approaches as well as (c) the use of Data Science as a bridge for handling and coupling big forest health data with volume, velocity, variety and veracity.

\section{ACKNOWLEDGEMENTS}

We truly appreciate the support that we received from the project "GEOEssential-Essential Variables workflows for resource efficiency and environmental management." The contribution of M.E.S. is supported by the University of Zurich Research Priority Program on 'Global Change and Biodiversity'. The authors also thank the reviewers for their very valuable comments and recommendations.

\section{AUTHORS' CONTRIBUTIONS}

All authors contributed to the development and writing of the manuscript.

\section{DATA ACCESSIBILITY}

I confirm that my manuscript does not include any data.

\section{ORCID}

Angela Lausch (iD http://orcid.org/0000-0002-4490-7232

Stefan Klotz iD http://orcid.org/0000-0003-4355-6415

Pedro J. Leitão (iD http://orcid.org/0000-0003-3038-9531

András Jung (iD http://orcid.org/0000-0003-3250-4097

Duccio Rocchini (iD http://orcid.org/0000-0003-0087-0594

Michael E. Schaepman (iD http://orcid.org/0000-0002-9627-9565

Andrew K. Skidmore iD http://orcid.org/0000-0002-7446-8429

Sonja Knapp (iD http://orcid.org/0000-0001-5792-4691

\section{REFERENCES}

Asner, G. P., Anderson, C. B., Martin, R. E., Tupayachi, R., Knapp, D. E., \& Sinca, F. (2015). Landscape biogeochemistry reflected in shifting distributions of chemical traits in the Amazon forest canopy. Nature Geoscience, 8, 567-573. https://doi.org/10.1038/ngeo2443

Asner, G. P., Knapp, D. E., Martin, R. E., Tupayachi, R., Anderson, C. B., Mascaro, J., ... Silman, M. R. (2014). Targeted carbon conservation at national scales with high-resolution monitoring. Proceedings of the National Academy of Sciences of the United States of America, 111, E5016-E5022. https://doi.org/10.1073/pnas.1419550111

Asner, G. P., \& Martin, R. E. (2016). Spectranomics: Emerging science and conservation opportunities at the interface of biodiversity and remote sensing. Global Ecology and Conservation, 8, 212-219. https:// doi.org/10.1016/j.gecco.2016.09.010

Atkin, O. K., Bloomfield, K. J., Reich, P. B., Tjoelker, M. G., Asner, G. P., Bonal, D., ... Zaragoza-Castells, J. (2015). Global variability in leaf respiration in relation to climate, plant functional types and leaf traits. New Phytologist, 206, 614-636. https://doi.org/10.1111/ nph.13253

Avitabile, V., Herold, M., Heuvelink, G. B. M., Lewis, S. L., Phillips, O. L., Asner, G. P., ... Willcock, S. (2016). An integrated pan-tropical biomass map using multiple reference datasets. Global Change Biology, 22, 1406-1420. https://doi.org/10.1111/gcb.13139

Ayris, P., Berthou, J.-Y., Bruce, R., Lindstaedt, S., Monreale, A., Mons, B., ... Wilkinson, R. (2016). Realising the European Open Science Cloud. European Commission B-1049 Brussels. https://ec.europa.eu/ research/openscience/pdf/realising_the_european_open_science_ cloud_2016.pdf

Baldeck, C., \& Asner, G. (2013). Estimating vegetation beta diversity from airborne imaging spectroscopy and unsupervised clustering. Remote Sensing, 5, 2057-2071. https://doi.org/10.3390/rs5052057

Balzotti, C. S., Asner, G. P., Taylor, P. G., Cleveland, C. C., Cole, R., Martin, R. E., ... Townsend, A. R. (2016). Environmental controls on canopy 
foliar $\mathrm{N}$ distributions in a neotropical lowland forest. Ecological Applications, 26, 2449-2462.

Berners-Lee, T. (2006). Computer science: Enhanced: Creating a science of the web. Science, 313, 769-771. https://doi.org/10.1126/ science. 1126902

Bruelheide, H., Nadrowski, K., Assmann, T., Bauhus, J., Both, S., Buscot, F., ... Schmid, B. (2014). Designing forest biodiversity experiments: General considerations illustrated by a new large experiment in subtropical China. Methods in Ecology and Evolution, 5, 74-89. https://doi.org/10.1111/2041-210X.12126

Bush, A., Sollmann, R., Wilting, A., Bohmann, K., Cole, B., Balzter, H., ... Yu, D. W. (2017). Connecting earth observation to high-throughput biodiversity data. Nature Ecology \& Evolution, 1, 176. https://doi. org/10.1038/s41559-017-0176

Bustamante, M. M. C., Roitman, I., Aide, T. M., Alencar, A., Anderson, L. O., Aragão, L., ... Vieira, I. C. G. (2016). Toward an integrated monitoring framework to assess the effects of tropical forest degradation and recovery on carbon stocks and biodiversity. Global Change Biology, 22, 92-109.

Cadotte, M. W. (2013). Experimental evidence that evolutionarily diverse assemblages result in higher productivity. Proceedings of the National Academy of Sciences of the United States of America, 110, 8996-9000. https://doi.org/10.1073/pnas.1301685110

Carboni, M., de Bello, F., Janeček, Š., Doležal, J., Horník, J., Lepš, J., ... Klimešová, J. (2014). Changes in trait divergence and convergence along a productivity gradient in wet meadows. Agriculture, Ecosystems and Environment, 182, 96-105. https://doi.org/10.1016/ j.agee.2013.12.014

Cardinale, B. J., Duffy, J. E., Gonzalez, A., Hooper, D. U., Perrings, C., Venail, P., ... Naeem, S. (2012). Biodiversity loss and its impact on humanity. Nature, 486, 59-67. https://doi.org/10.1038/nature11148

Cheptou, P.-O., Carrue, O., Rouifed, S., \& Cantarel, A. (2008). Rapid evolution of seed dispersal in an urban environment in the weed Crepis sancta. Proceedings of the National Academy of Sciences of the United States of America, 105, 3796-3799. https://doi.org/10.1073/ pnas. 0708446105

Cleland, E. E., Chuine, I., Menzel, A., Mooney, H. A., \& Schwartz, M. D. (2007). Shifting plant phenology in response to global change. Trends in Ecology and Evolution, 22, 357-365. https://doi. org/10.1016/j.tree.2007.04.003

Deans, A. R., Lewis, S. E., Huala, E., Anzaldo, S. S., Ashburner, M., Balhoff, J. P., ... Mabee, P. (2015). Finding our way through phenotypes. PLoS Biology, 13, e1002033.

Díaz, S., Kattge, J., Cornelissen, J. H. C., Wright, I. J., Lavorel, S., Dray, S., ... Gorné, L. D. (2015). The global spectrum of plant form and function. Nature, 529, 1-17.

Díaz, S., Lavorel, S., Mclntyre, S., Falczuk, V., Casanoves, F., Milchunas, D. G., ... Campbell, B. D. (2007). Plant trait responses to grazing A global synthesis. Global Change Biology, 13, 313-341. https://doi. org/10.1111/j.1365-2486.2006.01288.x

Dinnage, R., Cadotte, M. W., Haddad, N. M., Crutsinger, G. M., \& Tilman, D. (2012). Diversity of plant evolutionary lineages promotes arthropod diversity. Ecology Letters, 15, 1308-1317. https://doi. $\operatorname{org} / 10.1111 / \mathrm{j} .1461-0248.2012 .01854 . x$

Eldredge, N., \& Cracraft, J. (1980). Phylogenetic patterns and the evolutionary process. New York, NY: Columbia University Press.

Faith, D. P. (1992). Conservation evaluation and phylogenetic diversity. Biological Conservation, 61, 1-10. https://doi. org/10.1016/0006-3207(92)91201-3

Flynn, D. F. B., Mirotchnick, N., Jain, M., Palmer, M. I., \& Naeem, S. (2011). Functional and phylogenetic diversity as predictors of biodiversityecosystem-function relationships. Ecology, 92, 1573-1581. https:// doi.org/10.1890/10-1245.1

Frishkoff, L. O., Karp, D. S., M'Gonigle, L. K., Hadly, E. A., \& Daily, G. C. (2014). Loss of avian phylogenetic diversity in neotropical agricutural systems. Science, 345, 1343-1346. https://doi.org/10.1126/ science. 1254610

Furbank, R. T. (2009). Foreword: Plant phenomics: From gene to form and function. Functional Plant Biology, 36, v.

Garnier, E., Lavorel, S., Ansquer, P., Castro, H., Cruz, P., Dolezal, J., ... Zarovali, M. P. (2007). Assessing the effects of land-use change on plant traits, communities and ecosystem functioning in grasslands: A standardized methodology and lessons from an application to 11 European sites. Annals of Botany, 99, 967-985. https://doi. org/10.1093/aob/mcl215

Garonna, I., de Jong, R., \& Schaepman, M. E. (2016). Variability and evolution of global land surface phenology over the past three decades (1982-2012). Global Change Biology, 22, 1456-1468. https://doi. org/10.1111/gcb.13168

Gómez Giménez, M., de Jong, R., Della Peruta, R., Keller, A., \& Schaepman, M. E. (2017). Determination of grassland use intensity based on multi-temporal remote sensing data and ecological indicators. Remote Sensing of Environment, 198, 126-139. https://doi. org/10.1016/j.rse.2017.06.003

Grace, J. B., Anderson, T. M., Seabloom, E. W., Borer, E. T., Adler, P. B., Harpole, W. S., ... Smith, M. D. (2016). Integrative modelling reveals mechanisms linking productivity and plant species richness. Nature, 529, 390-393. https://doi.org/10.1038/nature16524

Green, J. L., Bohannan, J. M., \& Whitaker, R. J. (2008). Microbial biogeography: From taxonomy to traits. Science, 320, 1039-1043. https:// doi.org/10.1126/science.1153475

Grube, M., \& Kroken, S. (2016). Molecular approaches and the concept of species and species complexes in lichenized fungi Molecular approaches and the concept of species and species complexes in lichenized fungi. Mycological Research, 104, 1284-1294.

Guay, K. C., Beck, P. S. A., Berner, L. T., Goetz, S. J., Baccini, A., \& Buermann, W. (2014). Vegetation productivity patterns at high northern latitudes: A multi-sensor satellite data assessment. Global Change Biology, 20, 3147-3158. https://doi.org/10.1111/ gcb.12647

Haase, P., Tonkin, J. D., Stoll, S., Burkhard, B., Frenzel, M., Geijzendorffer, I. R., ... Schmeller, D. S. (2018). The next generation of site-based long-term ecological monitoring: Linking essential biodiversity variables and ecosystem integrity. Science of the Total Environment, 613614, 1376-1384. https://doi.org/10.1016/j.scitotenv.2017.08.111

Homolová, L., Maenovsky, Z., Clevers, J. G. P. W., Garcia-Santos, G., \& Schaepman, M. E. (2013). Review of optical-based remote sensing for plant trait mapping. Ecological Complexity, 15, 1-16. https://doi. org/10.1016/j.ecocom.2013.06.003

Hutchinson, G. E. (1965). The ecological theater and the evolutionary play. New Haven, CT: Yale University Press.

Isbell, F., Craven, D., Connolly, J., Loreau, M., Schmid, B., Beierkuhnlein, C., ... Eisenhauer, N. (2015). Biodiversity increases the resistance of ecosystem productivity to climate extremes. Nature, 526, 574-U263.

Jeong, S. J., Ho, C. H., Gim, H. J., \& Brown, M. E. (2011). Phenology shifts at start vs. end of growing season in temperate vegetation over the Northern Hemisphere for the period 19822008. Global Change Biology, 17, 2385-2399. https://doi. org/10.1111/j.1365-2486.2011.02397.x

Jetz, W., Cavender-Bares, J., Pavlick, R., Schimel, D., Davis, F. W., Asner, G. P., ... Ustin, S. L. (2016). Monitoring plant functional diversity from space. Nature Plants, 2, 1-5.

Kattge, J., Díaz, S., Lavorel, S., Prentice, I. C., Leadley, P., Bönisch, G., ... Wirth, C. (2011). TRY - A global database of plant traits. Global Change Biology, 17, 2905-2935. https://doi.org/10.1111/ j.1365-2486.2011.02451.x

Knapp, S., Kühn, I., Schweiger, O., \& Klotz, S. (2008). Challenging urban species diversity: Contrasting phylogenetic patterns across plant functional groups in Germany. Ecology Letters, 11, 1054-1064. https://doi.org/10.1111/j.1461-0248.2008.01217.x 
Knapp, S., Winter, M., \& Klotz, S. (2017). Increasing species richness but decreasing phylogenetic richness and divergence over a 320-year period of urbanization. Journal of Applied Ecology, 54, 1152-1160. https://doi.org/10.1111/1365-2664.12826

Knyazikhin, Y., Schull, M. A., Stenberg, P., Mottus, M., Rautiainen, M., Yang, Y., ... Myneni, R. B. (2013). Hyperspectral remote sensing of foliar nitrogen content. Proceedings of the National Academy of Sciences of the United States of America, 110, E185-E192. https://doi. org/10.1073/pnas.1210196109

Kraft, S., Del Bello, U., Bouvet, M., Drusch, M., \& Moreno, J. (2012). FLEX: ESA's Earth Explorer 8 candidate mission. International Geoscience and Remote Sensing Symposium (IGARSS), 1, 7125-7128.

Laity, T., Laffan, S. W., González-Orozco, C. E., Faith, D. P., Rosauer, D. F., Byrne, M., \& Newport, K. (2015). Phylodiversity to inform conservation policy: An Australian example. Science of the Total Environment, 534, 131-143. https://doi.org/10.1016/ j.scitotenv.2015.04.113

Laurin, G. V., Puletti, N., Hawthorne, W., Liesenberg, V., Corona, P., Papale, D., ... Valentini, R. (2016). Discrimination of tropical forest types, dominant species, and mapping of functional guilds by hyperspectral and simulated multispectral Sentinel-2 data. Remote Sensing of Environment, 176, 163-176. https://doi.org/10.1016/ j.rse.2016.01.017

Lausch, A., Bannehr, L., Beckmann, M., Boehm, C., Feilhauer, H., Hacker, J. M., ... Cord, A. F. (2016). Linking earth observation and taxonomic, structural and functional biodiversity: Local to ecosystem perspectives. Ecological Indicators, 70, 317-339. https://doi.org/10.1016/ j.ecolind.2016.06.022

Lausch, A., Blaschke, T., Haase, D., Herzog, F., Syrbe, R.-U., Tischendorf, L., \& Walz, U. (2015). Understanding and quantifying landscape structure - A review on relevant process characteristics, data models and landscape metrics. Ecological Modelling, 295, 31-41.

Lausch, A., Borg, E., Bumberger, J., Dietrich, P., Heurich, M., Huth, A., ... Schaepman, M. E. (in review). Understanding forest health with remote sensing -Part III - Requirements for a scalable multi-source forest health monitoring network. Remote Sensing.

Lausch, A., Erasmi, S., King, D. J., Magdon, P., \& Heurich, M. (2016). Understanding forest health by remote sensing - Part I - A review of spectral traits, processes and remote sensing characteristics. Remote Sensing, 8, 1029. https://doi.org/10.3390/rs8121029

Lausch, A., Erasmi, S., King, D., Magdon, P., \& Heurich, M. (2017). Understanding forest health with remote sensing-part II - A review of approaches and data models. Remote Sensing, 9, 129. https://doi. org $/ 10.3390 /$ rs 9020129

Lausch, A., Schmidt, A., \& Tischendorf, L. (2015). Data mining and linked open data - New perspectives for data analysis in environmental research. Ecological Modelling, 295, 5-17.

Lawton, J. H., Naeem, S., Woodfin, R. M., Brown, V. K., Gange, A., Godfray, H. C. J., ... Young, S. (1993). The Ecotron: A controlled environmental facility for the investigation of population and ecosystem processes. Philosophical Transactions: Biological Sciences, 341, 181-194. https:// doi.org/10.1098/rstb.1993.0102

Lees, K. J., Quaife, T., Artz, R. R. E., Khomik, M., \& Clark, J. M. (2018). Potential for using remote sensing to estimate carbon fluxes across northern peatlands - A review. Science of the Total Environment 615, 857-874. https://doi.org/10.1016/j.scitotenv.2017.09.103

Leitão, P. J., Schwieder, M., Suess, S., Okujeni, A., Galvão, L. S., van der Linden, S., \& Hostert, P. (2015). Monitoring natural ecosystem and ecological gradients: Perspectives with EnMAP. Remote Sensing, 7 , 13098-13119. https://doi.org/10.3390/rs71013098

Lopatin, J., Fassnacht, F. E., Kattenborn, T., \& Schmidtlein, S. (2017). Mapping plant species in mixed grassland communities using close range imaging spectroscopy. Remote Sensing of Environment, 201, 12-23. https://doi.org/10.1016/j.rse.2017.08.031
Lososová, Z., Čeplová, N., Chytrý, M., Tichý, L., Danihelka, J., Fajmon, K., ... Řehořek, V. (2016). Is phylogenetic diversity a good proxy for functional diversity of plant communities? A case study from urban habitats. Journal of Vegetation Science, 27, 1036-1046. https://doi. org/10.1111/jvs.12414

Madin, J. S., Bowers, S., Schildhauer, M. P., \& Jones, M. B. (2008). Advancing ecological research with ontologies. Trends in Ecology and Evolution, 23, 159-168. https://doi.org/10.1016/j.tree.2007. 11.007

Marcon, E., \& Hérault, B. (2015). Decomposing phylodiversity. Methods in Ecology and Evolution, 6, 333-339. https://doi. org/10.1111/2041-210X.12323

Martin, R., Chadwick, K., Brodrick, P., Carranza-Jimenez, L., Vaughn, N., \& Asner, G. (2018). An approach for foliar trait retrieval from airborne imaging spectroscopy of tropical forests. Remote Sensing, 10, 199. https://doi.org/10.3390/rs10020199

Mayr, E. (1942). Systematics and the origin of species: From the viewpoint of a zoologist. New York, NY: Columbia University Press.

Mayr, E. (1969). The biological meaning of species. Biological Journal of the Linnean Society, 1, 311-320. https://doi.org/10.1111/j.1095-8312. 1969.tb00123.x

Mayr, E., \& Ashlock, P. D. (1969). Principles of systematic zoology. New York, NY: McGrawHill.

Mueller, F., Baessler, C., Schubert, H., \& Klotz, S. (2010). Term ecological research. Between theory and application. Dordrecht, The Netherlands: Springer Science + Business Media B.V. https://doi. org/10.1007/978-90-481-8782-9

Müller, F. (2005). Indicating ecosystem and landscape organisation. Ecological Indicators, 5, 280-294. https://doi.org/10.1016/j. ecolind.2005.03.017

Pandey, P., Ge, Y., Stoerger, V., \& Schnable, J. C. (2017). High throughput in vivo analysis of plant leaf chemical properties using hyperspectral imaging. Frontiers in Plant Science, 8, 1-12.

Pereira, H. M., Ferrier, S., Walters, M., Geller, G. N., Jongman, R. H. G., Scholes, R. J., ... Wegmann, M. (2013). Ecology. Essential biodiversity variables. Science, 339, 277-278. https://doi.org/10.1126/ science.1229931

Pyšek, P., Jarošík, V., Hulme, P. P. E., Kühn, I., Wild, J., Arianoutsou, M., ... Winter, M. (2010). Disentangling the role of environmental and human pressures on biological invasions across Europe. Proceedings of the National Academy of Sciences of the United States of America, 107, 12157-12162.

Rapport, D. J., Costanza, R., \& McMichael, A. J. (1998). Assessing ecosystem health. Trends in Ecology and Evolution, 13, 397-402. https://doi. org/10.1016/S0169-5347(98)01449-9

Richter, R., Reu, B., Wirth, C., \& Doktor, D. (2016). The use of airborne hyperspectral data for tree species classification in a speciesrich Central European forest area. International Journal of Applied Earth Observation and Geoinformation, 52, 464-474. https://doi. org/10.1016/j.jag.2016.07.018

Rocchini, D., Bacaro, G., Chirici, G., Da Re, D., Feilhauer, H., Foody, G. M., ... Rugani, B.(2018). Remotely sensed spatial heterogeneity as an exploratory tool for taxonomic and functional diversity study. Ecological Indicators, 85, 983-990. https://doi.org/10.1016/j. ecolind.2017.09.055

Rocchini, D., Balkenhol, N., Carter, G. A., Foody, G. M., Gillespie, T. W. He, K. S., ... Neteler, M. (2010). Remotely sensed spectral heterogeneity as a proxy of species diversity: Recent advances and open challenges. Ecological Informatics, 5, 318-329. https://doi.org/10.1016/j. ecoinf.2010.06.001

Rocchini, D., Hernández-Stefanoni, J. L., \& He, K. S. (2015). Advancing species diversity estimate by remotely sensed proxies: A conceptual review. Ecological Informatics, 25, 22-28. https://doi.org/10.1016/j. ecoinf.2014.10.006 
Rocchini, D., Luque, S., Pettorelli, N., Bastin, L., Doktor, D., Faedi, N., ... Nagendra, H. (2017). Measuring $\beta$-diversity by remote sensing: a challenge for biodiversity monitoring. Methods in Ecology and Evolution, 2017, 1-11.

Römermann, C., Tackenberg, O., Jackel, A. K., \& Poschlod, P. (2008). Eutrophication and fragmentation are related to species' rate of decline but not to species rarity: Results from a functional approach. Biodiversity and Conservation, 17, 591-604. https://doi.org/10.1007/ s10531-007-9283-2

Santos, M. J., Khanna, S., Hestir, E. L., Greenberg, J. A., \& Ustin, S. L. (2016). Measuring landscape-scale spread and persistence of an invaded submerged plant community from airborne remote sensing. Ecological Applications, 26, 1733-1744. https://doi.org/10.1890/15-0615

Schimel, D. S., Asner, G. P., \& Moorcroft, P. (2013). Observing changing ecological diversity in the Anthropocene. Frontiers in Ecology and the Environment, 11, 129-137.

Schimel, D., Pavlick, R., Fisher, J. B., Asner, G. P., Saatchi, S., Townsend, P., ... Cox, P. (2015). Observing terrestrial ecosystems and the carbon cycle from space. Global Change Biology, 21, 1762-1776. https://doi. org/10.1111/gcb.12822

Schmidt, K. S., \& Skidmore, A. K. (2003). Spectral discrimination of vegetation types in a coastal wetland. Remote Sensing of Environment, 85, 92-108. https://doi.org/10.1016/S0034-4257(02)00196-7

Schneider, F. D., Morsdorf, F., Schmid, B., Petchey, O. L., Hueni, A., Schimel, D. S., \& Schaepman, M. E. (2017). Mapping functional diversity from remotely sensed morphological and physiological forest traits. Nature Communications, 8, 1441. https://doi.org/10.1038/s41467-017-01530-3

Schweiger, A. K., Cavender-bares, J., Townsend, P. A., Hobbie, S. E., Madritch, M. D., Wang, R., ... Gamon, J. A. (2018). Phylogenetic components of biodiversity and predicts ecosystem function. Nature Ecology \& Evolution, 2, 976-982.https://doi.org/10.1038/s41559-018-0551-1

Schweiger, O., Klotz, S., Durka, W., \& Kühn, I. (2008). A test of phylogenetic diversity indices. Oecologia, 157, 485-495. https://doi. org/10.1007/s00442-008-1082-2

Sechrest, W., Brooks, T. M., da Fonseca, G. A. B., Konstant, W. R., Mittermeier, R. A., Purvis, A., ... Gittleman, J. L. (2002). Hotspots and the conservation of evolutionary history. Proceedings of the National Academy of Sciences of the United States of America, 99, 2067-2071. https://doi.org/10.1073/pnas.251680798

Skidmore, A. K., Pettorelli, N., Coops, N. C., Geller, G. N., Hansen, M., Lucas, R., ... Wegmann, M. (2015). Environmental science: Agree on biodiversity metrics to track from space. Nature, 523, 403-405. https://doi.org/10.1038/523403a

Soberón, J. (2007). Grinnellian and Eltonian niches and geographic distributions of species. Ecology Letters, 10, 1115-1123. https://doi. org/10.1111/j.1461-0248.2007.01107.x

Turner, W. (2014). Sensing biodiversity. Science, 346, 301-303.
Ustin, S. L. (2013). Remote sensing of canopy chemistry. Proceedings of the National Academy of Sciences of the United States of America, 110, 804-805. https://doi.org/10.1073/pnas.1219393110

Ustin, S. L., \& Gamon, J. A. (2010). Remote sensing of plant functional types. New Phytologist, 186, 795-816. https://doi. org/10.1111/j.1469-8137.2010.03284.x

Ustin, S. L., Gitelson, A. A., Jacquemoud, S., Schaepman, M., Asner, G. P., Gamon, J. A., \& Zarco-Tejada, P. (2009). Retrieval of foliar information about plant pigment systems from high resolution spectroscopy. Remote Sensing of Environment, 113, S67-S77.

vanKleunen, M.,Weber, E., \&Fischer,M.(2010).Ameta-analysis of traitdifferences between invasive and non-invasive plant species. Ecology Letters, 13, 235-245. https://doi.org/10.1111/j.1461-0248.2009.01418.x

Violle, C., Reich, P. B., Pacala, S. W., Enquist, B. J., \& Kattge, J. (2014). The emergence and promise of functional biogeography. Proceedings of the National Academy of Sciences of the United States of America, 111, 13690-13696. https://doi.org/10.1073/ pnas.1415442111

Wellmann, T., Haase, D., Knapp, S., Salbach, C., Selsam, P., \& Lausch, A. (2018). Urban land use intensity assessment: The potential of spatiotemporal spectral traits with remote sensing. Ecological Indicators, 85 , 190-203.

Wheeler, Q. D., \& Meier, R. (2000). Species concepts and phylogenetic theory. New York, NY: Columbia University Press.

Wilkinson, M. D., Dumontier, M., Aalversberg, I. J., Appleton, G., \& Axton, M. (2016). Comment: The FAIR guiding principles for scientific data management and stewardship. Nature Communications, 3, 1-9.

Willis, C. G., Ruhfel, B., Primack, R. B., Miller-Rushing, A. J., \& Davis, C. C. (2008). Phylogenetic patterns of species loss in Thoreau's woods are driven by climate change. Proceedings of the National Academy of Sciences of the United States of America, 105, 17029-17033. https:// doi.org/10.1073/pnas.0806446105

Wright, A. J., de Kroon, H., Visser, E. J. W., Buchmann, T., Ebeling, A., Eisenhauer, N., ... Mommer, L. (2017). Plants are less negatively affected by flooding when growing in species-rich plant communities. New Phytologist, 213, 645-656.

Wulder, M. A., \& Coops, N. C. (2014). Make Earth observations open access. Nature, 513, 30-31. https://doi.org/10.1038/513030a

How to cite this article: Lausch A, Bastian O, Klotz S, et al. Understanding and assessing vegetation health by in situ species and remote-sensing approaches. Methods Ecol Evol. 2018;9:1799-1809. https://doi.org/10.1111/2041-210X.13025 